- Martin RH, Glass MR, Chapman C, Wilson GD, Woods KL. Human lactalbumin and hormonal factors in pregnancy and lactation. Clin Endocrinol (in press).

5 Waterhouse JAH. Cancer handbook of epidemiology and prognosis. Edinburgh: Churchill-Livingstone, 1974.

${ }^{6}$ Office of Population, Censuses and Surveys. Birth statistics, England and Wales, 1974. I.ondon: HMSO, 1977.

${ }^{7}$ McGuire WL, Carbone PP, Sears ME, Escher GC. Estrogen receptors in human breast cancer: an overview. In: McGuire WL, Carbone PP, Vollmer EP, eds. Estrogen receptors in human breast cancer. New York: Raven Press, 1975.

${ }^{8}$ Moon RC. Relationship between previous reproductive history and chemically induced mammary cancer in rats. Int $\mathcal{F}$ Cancer $1969 ; 4: 312-7$.
- Dao TL, Sunderland H. Mammary carcinogenesis by 3-methylcholanthrene. I. Hormonal aspects in tumour induction and growth. $\mathrm{f}$ Natl Cancer Inst 1959;23:567-85.

${ }^{10}$ McCormick GM, Moon RC. Effect of pregnancy and lactation on growth of mammary tumours induced by 7,12 DMBA. Br $\mathcal{F}$ Cancer 1965;19: 160-6.

${ }^{11}$ Breslow L, Thomas LB, Upton AC. Final reports of the National Cancer Institute ad hoc working groups on mammography in screening for breast cancer and a summary report of their joint findings and recommendations. F Natl Cancer Inst 1977;59:467-541.

(Accepted 24 fune 1980)

\title{
Conjugal disharmony: a hitherto unrecognised cause of strokes
}

\author{
N MILLIGAN, MILNE ANDERSON
}

\section{Summary and conclusions}

Two women of reproductive age suffered strokes. Neither was taking oral contraceptives, and investigations showed no other causal factors. The radiological findings were characteristic of traumatic internal carotid artery occlusion, but neither patient gave a history of trauma. Only after further inquiry into the patients' social circumstances did it emerge that each had survived an attempt at strangulation by her husband.

Such a cause of stroke in young women should be considered when other causes of carotid artery occlusion cannot be identified.

\section{Introduction}

Strokes occurring in women of reproductive age are uncommon, and in many cases full investigation fails to detect a demonstrable cause. When such a catastrophe occurs, less common causes of strokes are sought such as blood dyscrasia, bacterial endocarditis, severe diabetes, hypertensive encephalopathy, intracranial tumour, and vascular syphilis. Oral contraceptives, particularly of high oestrogen content, have been aetiologically implicated recently, but the pathogenesis remains unclear. Disease of the extracranial vessels has come to be recognised as a common cause of stroke in older age groups, and this cause for stroke is often seen in younger patients. Bickerstaff, ${ }^{1}$ however, found that the lesion was probably in the distribution of the middle cerebral artery, and lesions of the carotid artery in the neck were uncommon. Recognition of the role of non-penetrating trauma in the pathogenesis of internal carotid artery occlusion has increased recently, and the clinical, pathological, and radiological features are now well described. ${ }^{2-6}$

We have recently seen two women of reproductive age who suffered strokes as the result of lesions of the internal carotid artery, which we believe to be a result of a hitherto unrecognised, but probably not uncommon, form of trauma to this vessel in the neck.

Midland Centre for Neurosurgery and Neurology, Smethwick, Warley, West Midlands B67 7JX

N MILLIGAN, MB, MRCP, registrar in neurology

MILNE ANDERSON, MB, MRCP, consultant neurologist

\section{Case reports}

CASE 1

Five weeks before admission to this centre, a fit woman aged 37 became mildly confused and complained of headache. Over the succeeding seven days she developed weakness of her right hand, right arm, the right side of her face, and her right leg, followed by sensory diminution in a similar distribution and difficulty with speech. Her left eyelid began to droop, and she was admitted to another hospital then transferred for neurological investigation. Reproductive and menstrual history was unremarkable, and she was not taking oral contraceptives.

On examination she was fully conscious and mildly dysphasic. There was left Horner's syndrome and mild weakness of the right side of her face and of her right arm, with hyperreflexia. Palpation of the carotid arteries in the neck was normal, and there were no bruits. Her heart was in sinus rhythm and her blood pressure $140 / 90 \mathrm{~mm} \mathrm{Hg}$.

Results of the following investigations were normal: haemoglobin concentration; white blood cell count; erythrocyte sedimentation rate; blood film; Wassermann reaction; urea, blood sugar, cholesterol, triglyceride, and electrolyte concentrations; liver function tests; skull and chest radiography; isotope brain scan; and electrocardiography. Left common carotid arteriography showed incomplete occlusion of the internal carotid artery $1.5 \mathrm{~cm}$ distal to the bifurcation (fig 1) with sparse flow upwards to fill the ophthalmic artery.
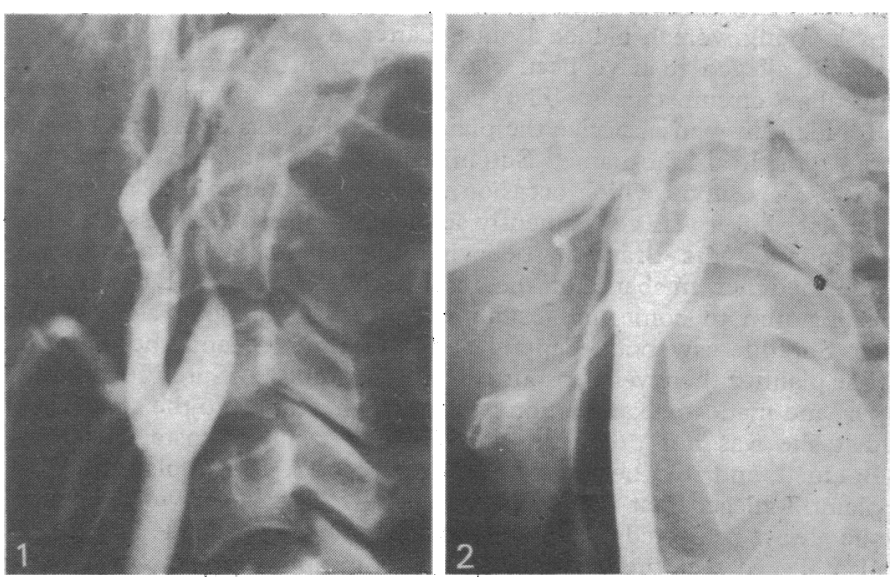

FIG 1-Case 1. Left carotid arteriogram showing almost complete block of internal carotid artery $1.5 \mathrm{~cm}$ distal to bifurcation. FIG 2-Case 2. Left carotid arteriogram showing occlusion of internal carotid artery $2 \mathrm{~cm}$ distal to bifurcation. 
After discharge from hospital she gradually improved, and eight years later her general practitioner reports that she is symptom free.

\section{CASE 2}

Seven days before transfer to this centre a woman aged 28 was admitted to another hospital, having been found by her husband in a collapsed state at home. She had a history of psychiatric illness and had taken drug overdoses in the past. For four years she had taken sulphasalazine and prednisone for ulcerative colitis, and two years before she had had an abortion. Her menstrual history was unremarkable, and she was not taking oral contraceptives.

On examination she was fully conscious but severely dysphasic with right homonymous hemianopia, hemiplegia, and hemisensory deficit. Carotid pulsation was normal, there were no bruits in the neck, and her blood pressure was $140 / 90 \mathrm{~mm} \mathrm{Hg}$. The heart was in sinus rhythm.

Results of the following investigations were normal: haemoglobin concentration; white blood cell count; erythrocyte sedimentation rate; blood film; Wassermann reaction; urea, blood sugar, cholesterol, triglyceride, and electrolyte concentrations; liver function tests; thyroid function tests; antinuclear factor titre; rheumatoid arthritis latex test; direct Coombs test; electrocardiography; and chest and skull radiography. Computed tomography of the brain showed a large area of infarction of the left frontoparietal region. Left common carotid arteriography showed tapering occlusion of the internal carotid artery $2 \mathrm{~cm}$ distal to the bifurcation, and only a meagre trickle of contrast medium ascended to the level of the syphon (fig 2).

Two years after discharge, her general practitioner reports that the only abnormality to be found is slight hesitancy of speech.

\section{Discussion}

Both women suffered strokes from lesions of the internal carotid artery in the neck. Both were in the reproductive age group, in which strokes from carotid artery disease are rare; and in neither case was any recognised aetiological factor identified, such as use of oral contraceptives, systemic hypertension, diabetes mellitus, blood dyscrasia, hyperlipidaemia, or heart disease. When we inquired into the social circumstances of each patient a likely explanation for the pathogenesis of the arterial lesion became evident. In each case there was considerable conjugal disharmony leading to not infrequent physical assault by one partner on the other. In the first case such an assault had taken place three days before the onset of symptoms and in the second case this had occurred the day before. Each patient had been seized around the neck in an attempt at strangulation, and in the second case the husband volunteered that "he had almost throttled his wife"; he was concerned that this may have contributed to her illness.

Occlusion of the internal carotid artery in the neck from nonpenetrating trauma is now well documented but is not always recognised clinically. The usual course of events is for symptoms to appear several hours or days, or as long as two weeks, after trauma. When there are signs of injury to the neck diagnosis is seldom a problem. Evidence of injury to the head or to some other part, however, may divert attention elsewhere. The site of the lesion is almost always in the internal carotid artery $1-3 \mathrm{~cm}$ distal to the bifurcation and has a characteristic tapering "rat's tail" appearance on arteriography, identical with those in our two cases. The pathogenesis is thought to be that trauma, either direct or indirect, results in a small intimal tear with subsequent dissection and thrombosis and perhaps distal embolisation. The development of these lesions explains why there is a latent period.

In these two cases we believe that the clinical history and findings of arteriography were characteristic of traumatic carotid artery occlusion, and we believe that attempted manual strangulation was the cause. We suggest that in any case of carotid artery occlusion in a young woman in whom a recognised aetiological factor cannot be identified inquiries (necessarily delicate and discreet) should be made to determine whether conjugal discord leading to violence has occurred.

We thank Miss Marion Smith for secretarial help.

Requests for reprints should be addressed to Dr Milne Anderson.

\section{References}

${ }^{1}$ Bickerstaff, ER. Neurological complications of oral contraceptives. 1st ed. Oxford: Clarendon Press, 1975.

2 Jernigan WR, Gardner WC. Carotid artery injuries due to closed cervical trauma. F Trauma $1971 ; 11: 429-35$.

3 Little JM, May J, Vanderfield GK, Lamond S. Traumatic thrombosis of the internal carotid artery, Lancet 1969 ;ii:926-31.

4 Pitner SE. Carotid thrombosis due to intraoral trauma. N Englf Med 1966; 274:764-7.

5 Yamada S, Kindt GW, Youmans JR. Carotid artery occlusion due to non-penetrating injury. $\mathcal{F}$ Trauma 1967;7:333-41.

6 Zilkha A. Traumatic occlusion of the internal carotid artery. Radiology $1970 ; 97: 543-8$.

(Accepted 30 fune 1980)
ONE HUNDRED YEARS AGO An action was recently tried before $\mathrm{Mr}$ Justice Lindley and a common jury, which was brought by a young woman named Louisa Latter, to recover damages for an assault alleged to have been committed upon her under somewhat peculiar circumstances. The defendants were Captain and Mrs Braddell, in whose service the plaintiff had been as domestic servant, and a medical man named Sutcliffe. The case had been tried at the last assizes, upon which occasion the jury were unable to agree to a verdict, and it was consequently set down again at these assizes. The defendant, Mrs Braddell, believing that the patient was enceinte, informed her husband of the fact; and he wrote to Dr Sutcliffe, asking him to come and examine his servant as soon as possible. Dr Sutcliffe saw both Captain and Mrs Braddell and the plaintiff. The plaintiff then went upstairs to her room, and Dr Sutcliffe followed her, and made an examination of her, which led him to the conclusion that she was not pregnant; and he then went downstairs to Mrs Braddell, and told her she had better apologise to the plaintiff. The plaintiff alleged that this was done entirely against her will, and that she always protested against any examination being made at all. She also alleged that the examination was improperly made, and that it might have been made without the amount of minute examination that was used. Dr Sutcliffe, on the other hand, denied that the plaintiff ever made any objection either to the examination or to the mode in which it was carried out, which, he said, was only the ordinary method.
Mr Justice Lindley ruled that, as far as Captain and Mrs Braddell were concerned, there was no evidence to show that they authorised or directed any examination of the plaintiff unless she consented, and, consequently, that there was no case for assault against them, and left it to the jury to say whether Dr Sutcliffe had either made the examination against the plaintiff's will or in an improper manner. The jury found in his favour on both points, and a verdict was entered for all the defendants. The issue of this case is thus satisfactory; but medical men cannot be too strongly cautioned never to undertake any examination of the kind except with the full consent of the individual given before witnesses. Neither the direction of a mistress nor a police-order suffices; the subject must assent of her own will. (British Medical fournal, 1880.)

\section{Correction}

Progestogens and cardiovascular reactions associated with oral contraceptives and a comparison of the safety of 50- and $30-\mu$ gestrogen preparations

An error occurred in this paper by Dr T W Meade and others (10 May, p 1157). The dates in table I should have read 1964-77, not 1968-77. 